\title{
Social inclusion, and the power of being 'seen' and 'heard' in 2018
}

Whose experiences, lives and values do we have most access to, and whose voices end up being heard or privileged? What does 'visibility' really mean in a world with a 24-hour media cycle, the opening up and democratisation of participatory models fuelled by social media, and increasing opportunities for direct representation which bypass traditional gatekeepers of information dissemination? From the protest at this year's World Cup final carried out by Russian feminist musicians and activist group Pussy Riot, to the Black Lives Matter movement, and the increasing popular resistance to the detention of asylum seekers in Australia, we see increasing examples of the lived experiences of those kept 'out of view'.

'Visibility' takes many forms. To be invisible is to be 'forgotten' - it is to have one's lived experience pushed to the edges of society and with it, knowledge and histories born of exclusion and struggle. As we strive toward more socially inclusive communities the voices of those who have been silenced continue to move centre stage. In this issue we present a collection of articles that draw our attention to the ways in which we can expand 'visibility' of diverse experience and voices, and with it, the possibilities for increased social inclusion and community capacity.

The first article in this edition, demonstrates the need to increase the visibility of social exclusion issues in the context of experiences of homelessness. Oudshoorn, Van Berkum and Van Loom provide us with a critical overview of women's homelessness in Canada, Australia, the United States, and the United Kingdom. The authors seek to make visible women's homelessness in these countries as they reclaim space for women's experiences within a dominant discourse that has often marginalised and invisibilised women's homelessness. Traversing a broad range of literature, the authors provide an historical review of women's homelessness beginning in the mid-1800s, tracing the various ways gender roles, social policy and legislation has shaped women's homelessness over time. They chart the ways in which gender norms and other structural forces have come to define not only the nature of women's homelessness but also the awareness of, and responses to, women's experiences of homelessness. The article therefore highlights the need to consider the influence of gender structures in understanding and addressing this often-hidden phenomenon.

In keeping with our theme of 'the power of being seen and heard', Malatzky, Mitchell and Bourke present a compelling argument that people's active participation and inclusion in rural health services is indeed a determinant of health status differentials. The authors note how exclusion of the most marginalised residents in rural communities results from entrenched power imbalances, and mainstream health service culture and practices, in particular, staff's difficulties understanding what cultural inclusion is and how this is operationalised within diverse communities. In response, an inclusive process is presented, using a participatory action research design and continuous quality improvement processes, informed by Foucault's notions of power, resistance and discourse. The result provides rural health services with a pragmatic approach to actively engaging with inclusivity, culture and power in order to achieve real change, or a shift in power relationships in the short term and reductions in health inequalities longer term.

In the article by Shelley, Donelly, Hillman, Dew, Whitaker, Stancliffe, Knox and Parmenter, the focus is on exploring how personal support networks can function to increase social inclusion through promoting social connectedness and community participation. Using data drawn from an ethnographic study conducted over a three-year period exploring the personal support networks of people living with an intellectual disability, we gain valuable insight into the ways 
in which informal systems and strategies are employed to provide meaningful and sustained support to the person with an intellectual disability. This article provides us with a detailed understanding into the often invisible and less well understood systems of care and support for people living with disabilities, derived from interpersonal relationships and networks within their own communities. Importantly the authors draw attention to the increased possibility for personal support networks to provide adaptable and respectful approaches than ensure the voices of those living with disabilities remain at the centre of the network.

In the article by Adonis and Couch, ili-based (or home based) community organising is not only seen as a culturally respectful, participatory approach, but one that privileges Indigenous peoples' voices and positions them as active contributors in the development of their communities. The concept of ili-based community organising arose out of work undertaken by non-government organisations with the Igorot Indigenous Peoples in Northern Philippines. As experiences of colonisation have left lgorot peoples feeling marginalised, the study engaged 36 participants to share their stories (in sharing circles) in relation to what development means to their community. The three findings which were revealed have practical applications for supporting community-led actions. These include the importance of incorporating traditional practices of working together in a community to resist the pressures associated with contemporary changes; the importance of reinvigorating cultural values, ethics and a sense of responsibility; and honouring relevant customary laws and the application of traditional decision-making.

Perhaps this edition's starkest demonstration of the need to ensure people are meaningfully included is provided in the article by Roy, McVilly and Crisp. The authors present the results of a small Australian study with a specialised group of professionals who work with people who are Deafblind $(n=8)$. The results of semi-structured interviews revealed six themes or principles to inform how practitioners and decision-makers can engage people who are Deafblind in consultation, research and for policy-related purposes. The article provides much needed guidance, including the core need to build on established, trusted relationships. It is therefore hoped that this guidance is used to realise authentic opportunities for active engagement, co-design and co-production in response to the identified gaps in the literature.

As we reflect on the myriad of ways that previously silenced voices come to the forefront of social justice debates, our challenge remains how do we find ways to genuinely 'see' and 'hear' from people who live on society's margins. The Netflix special 'Hannah Gadsby: Nanette' by Australian comedian Hannah Gadbsy (Gadsby \& Bruzzese, 2018) has been described as a 'game changer' for stand-up comedy, having successfully redefined the range of 'permissible' topics for debate and consideration in this particular art form (Scherer, 2018). Gadsby refers to her particular brand of self-deprecating humour as being born of the oppression she experienced growing up as a lesbian woman in Australia. Reflecting on this, Gadsby looks to the audience and asks "do you understand what self-deprecation means when it comes from somebody who already exists in the margins? It's not humility, it's humiliation. I put myself down in order to speak, in order to seek permission to speak, and I simply will not do that anymore" (Gadsby \& Bruzzese, 2018). United States children's rights activist Marian Wright Edelman once observed "you can't be what you can't see". Having lamented that she wished she had seen someone like herself when she was growing up, Gadsby explains "I learnt how to disappear...I was invisible. I learnt very early on. Well into my adult life, I was easily forgotten in a room, which meant I heard - I hear a lot" (cited in Ryzik, 2018).

The articles in this edition have demonstrated the need to radically shift norms, power relations, and social structures to ensure true inclusion and value diverse knowledge and perspectives. As editors of JOSI we look forward to the day when Hannah Gadsby's message is no longer considered 'groundbreaking' or 'radical', and a chorus of 'voices' from diverse perspectives increasingly define mainstream discourses. As JOSI moves forward and 
incorporates new digital platforms we aim to expand opportunities for a wider range of contributions to lead, challenge and stimulate further research and social action.

\section{Angella Duvnjak PhD}

Co-Editor

\section{Paul Harris $P h D$ \\ Co-Editor}

School of Human Services and Social Work

Griffith University

\author{
Australia
}




\section{References}

Gadsby, H. (Writer) \& Bruzzese, F. (Director) (2018, June 20). Hannah Gadsby: Nanette. Olb, J. \& Parry, M. (Producers), Sydney, NSW: Netflix.

Ryzik, M. (2018). 'The great Hannah Gadsby rewrites the rules of comedy', The Sydney Morning Herald, August 11th, https://www.smh.com.au/entertainment/comedy/thegreat-hannah-gadsby-rewrites-the-rules-of-comedy-20180807-p4zvyu.html

Scherer, J. (2018). 'Nanette': Hannah Gadsby on Her Game Changing Stand-up Special, Rolling Stone, July 9, retrieved from https://www.rollingstone.com/tv/tvfeatures/nanette-hannah-gadsby-on-her-gamechanging-stand-up-special-696354/ 